\title{
Electrical activity of carbon-hydrogen centers in $\mathrm{Si}$
}

\author{
O. Andersen and A. R. Peaker \\ Centre for Electronic Materials, UMIST, P.O. Box 88, Manchester M60 1QD, United Kingdom \\ L. Dobaczewski \\ Centre for Electronic Materials, UMIST, P.O. Box 88, Manchester M60 1QD, United Kingdom \\ and Institute of Physics, Polish Academy of Sciences, Warsaw, Poland
}

K. Bonde Nielsen
Institute of Physics and Astronomy, University of Aarhus, Aarhus, Denmark

B. Hourahine and R. Jones

School of Physics, The University of Exeter, Exeter EX4 4QL, United Kingdom

P. R. Briddon

Department of Physics, The University of Newcastle upon Tyne, Newcastle upon Tyne NE1 7RU, United Kingdom

S. Öberg

Department of Mathematics, Luleå University of Technology, S-97187 Luleå, Sweden

(Received 6 August 2002; published 13 December 2002)

\begin{abstract}
The electrical activity of $\mathrm{C}_{\mathrm{s}}-\mathrm{H}$ defects in Si has been investigated in a combined modeling and experimental study. High-resolution Laplace capacitance spectroscopy with the uniaxial stress technique has been used to measure the stress-energy tensor and the results are compared with theoretical modeling. At low temperatures, implanted $\mathrm{H}$ is trapped as a negative- $U$ center with a donor level in the upper half of the gap. However, at higher temperatures, $\mathrm{H}$ migrates closer to the carbon impurity and the donor level falls, crossing the gap. At the same time, an acceptor level is introduced into the upper gap making the defect a positive- $U$ center.
\end{abstract}

DOI: 10.1103/PhysRevB.66.235205

PACS number(s): 71.55.-i, 61.72.Bb, 85.40.Ry

\section{INTRODUCTION}

Isolated $\mathrm{H}$ in $\mathrm{Si}$ is a bistable species having a negative electron correlation energy $U \cdot \mathrm{H}^{0}$ and $\mathrm{H}^{+}$lie at bond centers with a donor level at $E_{c}-0.17 \mathrm{eV},{ }^{1,2}$ but $\mathrm{H}^{-}$lies near a $T$ site with a level around midgap. ${ }^{3-6}$ We shall show in this paper, using a combined experimental and theoretical investigation, that the presence of carbon profoundly alters this. In fact, $\mathrm{H}$ near carbon is a positive- $U$ species with donor and acceptor levels at $E_{v}+0.33$ and $E_{c}-0.16 \mathrm{eV}$, respectively. The latter being almost identical with the donor level of isolated $\mathrm{H}$. Further, $\mathrm{H}$ can be trapped as a metastable species, separated from substitutional carbon, and possesses an experimental donor level at $E_{c}-0.22 \mathrm{eV}$. Understandably, these properties have led to a great deal of confusion.

Carbon-hydrogen complexes have previously been studied using conventional deep level transient spectroscopy ${ }^{7-9}$ (DLTS). In the present work, we apply high-resolution Laplace deep level transient spectroscopy (Laplace DLTS ${ }^{10}$ ) combined with a uniaxial stress technique to investigate the $\mathrm{C}-\mathrm{H}$ defect. The application of stress to an anisotropic defect with charge $q$ changes its energy by $\operatorname{Tr}[B(q) \epsilon]$, where $B$ is the symmetric stress-energy tensor for the defect and $\epsilon$ the imposed strain tensor. The change in energy can result in a preferential alignment of the defect population and spectroscopic techniques such as magnetic resonance, infrared absorption, and luminescence ${ }^{11,12}$ have previously been used to determine $B$ for various defects. The effect of stress on $g$ tensors, vibrational modes, or luminescent transitions allows defects with different orientations to be distinguished through a splitting of the spectral lines. If the temperature is high enough so that reorientation of the defect can occur, then an equilibrium (Boltzmann) distribution of defects results directly related to the line intensity. In this way, the $B$ tensors for a number of defects have been found. ${ }^{11}$

In this paper, we show that Laplace DLTS can also lead to the determination of $B(q)$. Moreover, the splitting of say an acceptor level is related to the difference in the $B$ tensors of the two charge states, e.g., $B(-/ 0)=B(-)-B(0)$ and thus the stress Laplace DLTS experiment is unique in which the electrical level splitting, as well as equilibrium amplitudes, are governed by the $B$ tensor. The direct measurements of the capture process under stress showed that the stress does not influence the capture cross section and thus all stress-induced changes in the carrier emission rate come from the changes of the defect energy. In contrast, the splitting of luminescent centers is related to the effect of stress on both the optically excited and ground state, while the amplitude is governed by the rates of trapping and decay of photo-generated excitons.

Observations of the splitting or alignment of the DLTS lines then lead to the determination of the traceless parts of $B$, as a simple hydrostatic pressure does not split the spectral line. The stress splitting and alignment experiments can result in additional information. The symmetry of the center is reflected in the symmetry of the tensors and the rate at which alignment occurs gives the reorientation barrier of the 


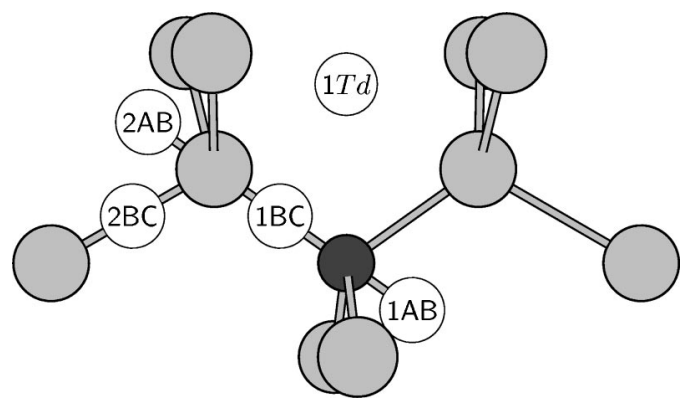

FIG. 1. Configurations of $\mathrm{H}$ near substitutional carbon (black circle). The hydrogen positions are labeled $x y$, where $x$ is the number of sites away from $\mathrm{C}_{\mathrm{s}}$ and $y$ is the type of site. $\mathrm{CH}_{1 \mathrm{BC}}$ is the lowest energy structure for the positive charge state with $\mathrm{CH}_{2 \mathrm{BC}}$ only $0.1 \mathrm{eV}$ higher in energy. $\mathrm{CH}_{1 \mathrm{BC}}$ is by far the most stable for the neutral charge state, while $\mathrm{CH}_{1 \mathrm{BC}}, \mathrm{CH}_{1 \mathrm{AB}}$, and $\mathrm{CH}_{1 T d}$ are all nearly degenerate in the negative charge state.

defect. ${ }^{11}$ It is also clear, that $B$ can be measured by more than one technique allowing correlated studies, and we show here that the measured values of $B$ are close to theoretical results. This is the first time that the stress response of a defect has been calculated with $a b$ initio methods and compared directly with experiment, to the best of our knowledge.

\section{A. Experimental technique}

The samples were prepared from a $20-\Omega \mathrm{cm}$ float zone $n$-type silicon wafer doped with $\sim 10^{17}-\mathrm{cm}^{-3}$ carbon atoms. The wafer had a (110) surface orientation. Samples were cut in the shape of $(1 \times 7 \times 2)$-mm blocks with the longest sample edge along one of the major crystallographic directions $(\langle 100\rangle,\langle 110\rangle$, and $\langle 111\rangle)$. Hydrogen-carbon complexes were created by either proton implantation at $70 \mathrm{~K}$ or wet etching at room temperature. The implantation was carried out under a reverse bias with an implant energy of 525 $\mathrm{keV}$ with a dose of $5 \times 10^{9} \mathrm{~cm}^{-2}$. The wet chemical etch used $\mathrm{HNO}_{3}$ and $\mathrm{HF}$ in the ratio 10:1. Reference samples prepared from as-grown oxygen-rich carbon-lean $20-\Omega \mathrm{cm}$ Czochralski $n$-type silicon were implanted with protons at 70 $\mathrm{K}$ under the same conditions as the carbon-rich samples.

Laplace Transform DLTS ${ }^{10}$ is an isothermal technique in which the emission rates of the capacitance transient are separated by mathematical routines. This produces a spectrum of spectral density function versus electron emission rate at the measurement temperature. The technique offers a substantially improved energy resolution compared to con-
TABLE I. Difference in energy, eV, of structures shown in Fig. 1. The calculation used $\mathrm{MP}^{2} k$ points with $\mathrm{H}\left(s_{3} p_{3}\right), \mathrm{C}\left(s_{4} p_{4} d_{4}\right)$, and $\operatorname{Si}\left(s_{4} p_{4} d_{2}\right)$ basis functions.

\begin{tabular}{lccc}
\hline \hline & + & 0 & - \\
\hline $\mathrm{CH}_{1 \mathrm{BC}}$ & 0.0 & 0.0 & 0.0 \\
$\mathrm{CH}_{1 \mathrm{AB}}$ & 0.6 & 0.5 & 0.2 \\
$\mathrm{CH}_{1 T d}$ & & 0.7 & 0.1 \\
$\mathrm{CH}_{2 \mathrm{BC}}$ & 0.2 & 0.6 & \\
$\mathrm{CH}_{2 \mathrm{AB}}$ & & 1.1 & 0.4 \\
\hline \hline
\end{tabular}

ventional DLTS, which makes it ideal for studying closely spaced energy levels and for uniaxial stress measurements.

\section{B. Theoretical technique}

A first-principles density-functional method ${ }^{13,14}$ is used, in conjunction with 64 atom cubic supercells containing the defects, to determine the energies, electrical levels, and stress tensors of different configurations (Fig. 1) of C-H defects. The wave functions of the defects were represented with a real-space Cartesian-Gaussian basis centered on each atom, with various numbers of independent $s, p$, and $d$ functions. The Hartree and Perdew-Zunger ${ }^{15}$ exchange-correlation energies were calculated using a 150-Ry plane-wave intermediate fit, with a Monkhorst-Pack (MD) $k$-point sampling scheme used to integrate over the band structure. ${ }^{16}$ The energies of the various stable structures considered are given in Table I, with the variation in relative energy for different calculations shown in Table II. It is clear that the energies and levels of different structures are converged to acceptable limits with both basis and $k$-point sampling.

The donor levels of the defects were obtained by use of the bulk ionization method of Jeong and Oshiyama, ${ }^{17,18}$ while the acceptor levels were calculated by extending the method to compare the energy of the neutral and negative defects against the energy of bulk cells in the neutral and negative charge states. The calculated levels and their sensitivity to basis size and $k$-point integration are shown in Tables III and IV.

The $B$ stress tensors for the defects were evaluated by compression of the defective cells. As an illustration of this method, the principal values of the $B(-/ 0)$ stress tensor for the vancancy-oxygen defect, which controls the splitting of the acceptor level under stress, were found to be 3.0, 2.3,

TABLE II. Relative energy difference, eV, between $\mathrm{CH}_{1 \mathrm{BC}}^{0}$ and $\mathrm{CH}_{1 \mathrm{AB}}^{0}$ for various calculational parameters. The relative energy is shown for different choices of Monkhorst-Pack (Ref. 16) $k$-points, different numbers of $s, p$, and $d$ functions in the atomic basis and different intermediate fitting cutoff energies.

\begin{tabular}{lccc}
\hline \hline$k$-point sampling & $\mathrm{MP}^{2}$ & $\mathrm{MP}^{4}$ & \\
\hline$E\left(\mathrm{CH}_{1 \mathrm{AB}}^{0}\right)-E\left(\mathrm{CH}_{1 \mathrm{BC}}^{0}\right)$ & 0.492 & 0.492 & \\
Basis & $\mathrm{C}\left(s_{4} p_{4} d_{2}\right) \mathrm{Si}\left(s_{4} p_{4} d_{2}\right)$ & $\mathrm{C}\left(s_{4} p_{4} d_{4}\right) \mathrm{Si}\left(s_{4} p_{4} d_{2}\right)$ & $\mathrm{C}\left(s_{4} p_{4} d_{4}\right) \operatorname{Si}\left(s_{4} p_{4} d_{3}\right)$ \\
$E\left(\mathrm{CH}_{1 \mathrm{AB}}^{0}\right)-E\left(\mathrm{CH}_{1 \mathrm{BC}}^{0}\right)$ & 0.494 & 0.492 & 0.503 \\
Cutoff $(\mathrm{Ry})$ & 125 & 150 & 175 \\
$E\left(\mathrm{CH}_{1 \mathrm{AB}}^{0}\right)-E\left(\mathrm{CH}_{1 \mathrm{BC}}^{0}\right)$ & 0.493 & 0.492 & 0.492 \\
\hline \hline
\end{tabular}


TABLE III. Calculated with experimental assignments when available in brackets of electrical levels, eV, relative to $E_{c}$, for $\mathrm{H}$ defects. The calculated levels refer to structures in Fig. 1.

\begin{tabular}{ccccccc}
\hline \hline & Isolated H & $\mathrm{CH}_{1 \mathrm{BC}}$ & $\mathrm{CH}_{1 \mathrm{AB}}$ & $\mathrm{CH}_{1 T d}$ & $\mathrm{CH}_{2 \mathrm{BC}}$ & $\mathrm{CH}_{2 \mathrm{AB}}$ \\
\hline$(-/ 0)^{\mathrm{d}}$ & $0.64\left(A T^{\prime}{ }^{\mathrm{a}}\right)$ & $0.30\left[(\mathrm{C}-\mathrm{H})_{\mathrm{II}}{ }^{\mathrm{c}}\right]$ & 0.63 & 0.89 & & 1.07 \\
$(0 /+)^{\mathrm{d}}$ & $0.27\left(E_{3}^{\prime a}\right)$ & $0.81\left(\mathrm{H}_{1}{ }^{\mathrm{b}}\right)$ & & & $0.40\left[(\mathrm{C}-\mathrm{H})_{\mathrm{I}}{ }^{\mathrm{c}}\right]$ & \\
$(-/ 0)^{\mathrm{e}}$ & & $0.48\left[(\mathrm{C}-\mathrm{H})_{\mathrm{II}}{ }^{\mathrm{c}}\right]$ & 0.82 & $>1.12$ & & \\
$(0 /+)^{\mathrm{e}}$ & $0.48\left(E_{3}^{\prime a}\right)$ & $0.82\left(\mathrm{H}_{1}{ }^{\mathrm{b}}\right)$ & & & $0.46\left[(\mathrm{C}-\mathrm{H})_{\mathrm{I}}{ }^{\mathrm{c}}\right]$ & \\
\hline \hline
\end{tabular}

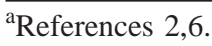

${ }^{\mathrm{b}}$ Reference 8 .

${ }^{\mathrm{c}}$ Reference 28 (this work).

${ }^{\mathrm{d}} \mathrm{MP}^{4} k$ points with $\mathrm{H}\left(s_{3} p_{3}\right), \mathrm{C}\left(s_{4} p_{4} d_{4}\right)$, and $\mathrm{Si}\left(s_{4} p_{4} d_{2}\right)$ basis functions.

${ }^{\mathrm{e}} \mathrm{MP}^{2} k$ points with $\mathrm{H}\left(s_{3} p_{3}\right), \mathrm{C}\left(s_{4} p_{4}\right), \mathrm{Si}\left(s_{4} p_{4}\right)$, and bond-centered polarization $s$ and $p$ functions.

$-5.0 \mathrm{eV}$ (Ref. 14) in good agreement with electron paramagnetic resonance (EPR) experimental values of 2.7, 2.7, $-5.3 \mathrm{eV}^{11}$

\section{EXPERIMENTAL RESULTS}

\section{A. Formation of $\mathrm{C}-\mathrm{H}$ complexes}

Figure 2(a) compares Laplace DLTS spectra, taken at 87 $\mathrm{K}$, of the carbon-rich and the oxygen-rich samples measured in situ after low-temperature proton implantation. The spectra reveal the appearance of two defects of large concentration in the carbon-rich samples. One of these defects is also observed in the oxygen-rich samples and has been already assigned to overlapping donor levels of isolated bondcentered hydrogen $\left(E_{3}^{\prime}\right)$ and bond-centered hydrogen perturbed by interstitial oxygen $\left(E_{3}^{\prime \prime}\right) .^{2,5}$ The other defect, labeled $(\mathrm{C}-\mathrm{H})_{\mathrm{I}}$, appears only in the carbon-rich samples. In the oxygen-rich samples, the well-known acceptor level of the vacancy-oxygen complex is observed in addition to the $E_{3}^{\prime} / E_{3}^{\prime \prime}$ level. The levels of the two defects are shown in Table $\mathrm{V}$.

The $(\mathrm{C}-\mathrm{H})_{\mathrm{I}}$ defect is not thermally stable. A short zerobias annealing at $110 \mathrm{~K}$ leads to the disappearance of both $(\mathrm{C}-\mathrm{H})_{\mathrm{I}}$ and $E_{3}^{\prime} / E_{3}^{\prime \prime}$ as illustrated in Fig. 2(b). Both levels, however, can be recovered by exposure to light. Figure 2(c) depicts Laplace spectra obtained after reverse bias illumination at $87 \mathrm{~K}$ of the zero-bias annealed samples. It is seen, that the $(\mathrm{C}-\mathrm{H})_{\mathrm{I}}$ level and the $E_{3}^{\prime \prime}$ levels are regenerated in the $\mathrm{C}$-rich and the O-rich samples, respectively. Both signals are increased in intensity compared to the as-implanted values, the signal increase being stronger for $(\mathrm{C}-\mathrm{H})_{\mathrm{I}}$. A small fraction of the $E_{3}^{\prime \prime}$ level is also observed in the C-rich samples in addition to $(\mathrm{C}-\mathrm{H})_{\mathrm{I}}$.

The observed transformations are well understood in the case of the O-rich samples. The loss of $E_{3}^{\prime} / E_{3}^{\prime \prime}$ upon zero-bias annealing at $110 \mathrm{~K}$ occurs by trapping two electrons forming $\mathrm{H}^{-}$lying at a $T$ site, a configuration not detected in the present experiment as its emission rate is too slow. Reverse bias illumination converts $\mathrm{H}_{T}^{-}$to $\mathrm{H}_{T}^{0}$, which diffuses freely through the crystal and eventually becomes trapped by interstitial oxygen, hereby forming the $E_{3}^{\prime \prime}$ level. The intensity increase after illumination is explained by a large fraction of hydrogen in the "hidden" $\mathrm{H}_{T}$ configuration after implantation. This $\mathrm{H}_{T}$ fraction can be observed as a slow capacitance transient referred to as $A T^{\prime}{ }^{6}$ The close similarity between the behavior of the $E_{3}^{\prime \prime}$ level in the O-rich samples and the $(\mathrm{C}-\mathrm{H})_{\mathrm{I}}$ level in the $\mathrm{C}$-rich samples suggest that the latter defect originates from a bond-center $\mathrm{H}$ configuration perturbed by a nearby carbon atom. This correlation will be discussed in further detail, shortly.

Figure 2(d) shows 87-K Laplace DLTS spectra measured after zero-bias anneal at $225 \mathrm{~K} .(\mathrm{C}-\mathrm{H})_{\mathrm{I}}$ is irreversibly lost upon this annealing and converts to another more stable hydrogen-carbon complex, $(\mathrm{C}-\mathrm{H})_{\mathrm{II}}$, the emission rate of this complex is similar to that of the acceptor level of the vacancy-oxygen complex. The conversion ratio between $(\mathrm{C}-\mathrm{H})_{\mathrm{I}}$ and $(\mathrm{C}-\mathrm{H})_{\mathrm{II}}$ is practically $1: 1$, indicating a simple atomic reconfiguration. The $(\mathrm{C}-\mathrm{H})_{\mathrm{II}}$ configuration is stable to just above room temperature (RT) and is also observed in samples wet etched in the dark at RT. It is irreversibly lost by

TABLE IV. Position of the $(-/ 0)$ electrical level, $\mathrm{eV}$, of $\mathrm{CH}_{1 \mathrm{BC}}$ with respect to the conduction band for various calculational parameters. The level position is shown as either a function of the number of for different choices of Monkhorst-Pack (Ref. 16) $k$ points, different numbers of $s, p$, and $d$ functions in the atomic basis and different intermediate fitting cutoff energies.

\begin{tabular}{lccc}
\hline \hline$k$-point sampling & $\mathrm{MP}^{2}$ & $\mathrm{MP}^{4}$ & \\
\hline \multirow{3}{*}{ Basis } & 0.378 & 0.304 & \\
& $\mathrm{C}\left(s_{4} p_{4} d_{2}\right) \operatorname{Si}\left(s_{4} p_{4} d_{2}\right)$ & $\mathrm{C}\left(s_{4} p_{4} d_{4}\right) \operatorname{Si}\left(s_{4} p_{4} d_{2}\right)$ & $\mathrm{C}\left(s_{4} p_{4} d_{4}\right) \operatorname{Si}\left(s_{4} p_{4} d_{3}\right)$ \\
& 0.378 & 0.378 & 0.349 \\
\hline \hline
\end{tabular}




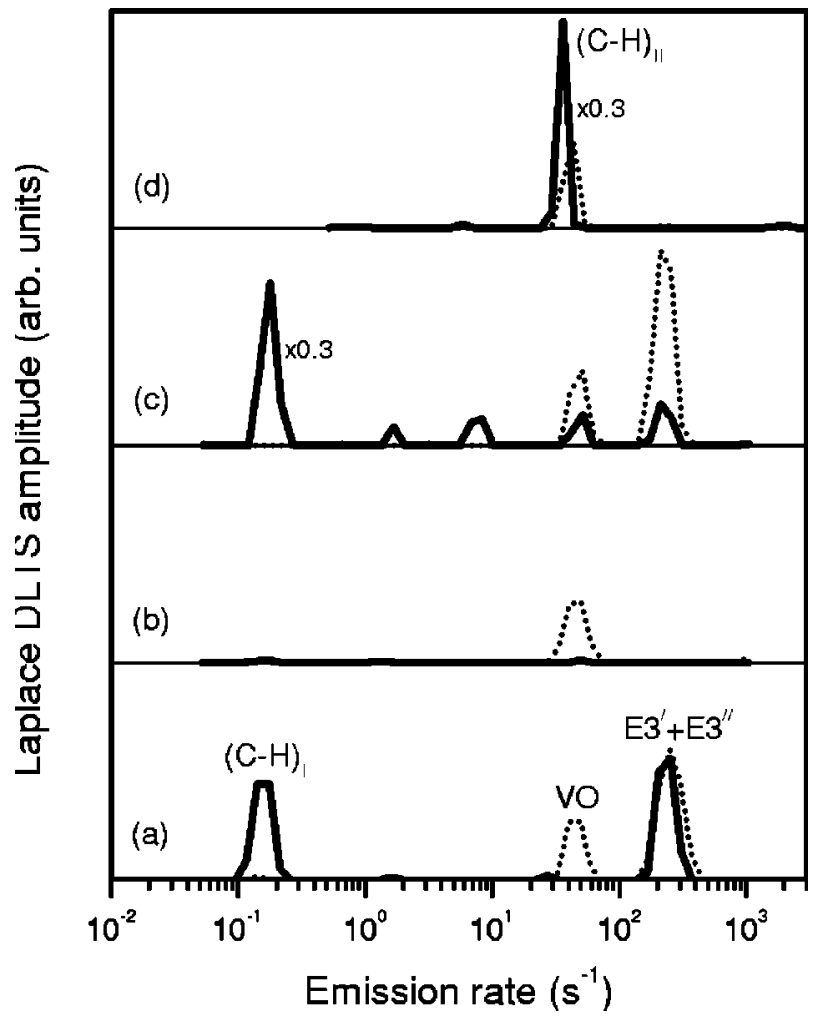

FIG. 2. Laplace DLTS spectra of $n$-type carbon-rich samples (solid lines) and oxygen-rich samples (dotted lines) measured in situ at $87 \mathrm{~K}$. (a) After proton implantation at $70 \mathrm{~K}$. (b) After zerobias annealing at $110 \mathrm{~K}$. (c) After illumination at $87 \mathrm{~K}$ under reverse bias of a sample treated as in (b). (d) After a subsequent zero-bias anneal at $225 \mathrm{~K}$.

white light illumination at RT whereupon no other levels are observed in the upper half of the gap. The $(\mathrm{C}-\mathrm{H})_{\mathrm{II}}$ level is identical to the carbon-hydrogen defect studied by Endrös et $a l^{7}$ and Kamiura et al. ${ }^{9,19}$

\section{B. Electronic properties of $(\mathrm{C}-\mathrm{H})_{\mathrm{I}}$ and $(\mathrm{C}-\mathrm{H})_{\mathrm{II}}$}

Figure 3 shows Arrhenius plots for the electron emission from $(\mathrm{C}-\mathrm{H})_{\mathrm{I}}$ and $(\mathrm{C}-\mathrm{H})_{\mathrm{II}}$. The Arrhenius analysis for $(\mathrm{C}-\mathrm{H})_{\mathrm{I}}$ gives an activation enthalpy $0.22 \mathrm{eV}$, with an electron capture cross section $2 \times 10^{-14} \mathrm{~cm}^{2}$. The magnitude of the capture cross section, similar to that in $E_{3}^{\prime}$ and $E_{3}^{\prime \prime}$, suggests a donor species, which is confirmed by the observation of an electric-field effect on the emission process as shown in Fig. 4. The observed field dependence complies with the three-

TABLE V. Observed electrical levels, eV, with respect to the conduction band.

\begin{tabular}{lccc}
\hline \hline & Isolated $\mathrm{H}$ & $\mathrm{C}$ related & C related \\
\hline$(-/ 0)$ & midgap $^{\mathrm{a}}$ & $0.16(\mathrm{C}-\mathrm{H})_{\mathrm{II}}{ }^{\mathrm{c}}$ & \\
$(0 /+)$ & $0.17, E_{3}^{\prime} / E_{3}^{\prime \prime \mathrm{a}}$ & $0.82, \mathrm{H}_{1}{ }^{\mathrm{c}}$ & $0.22(\mathrm{C}-\mathrm{H})_{\mathrm{I}}{ }^{\mathrm{c}}$ \\
\hline \hline
\end{tabular}

${ }^{\mathrm{a}}$ Reference 5 .

${ }^{\mathrm{b}}$ Reference 8 .

${ }^{\mathrm{c}}$ Reference 28 (this work).

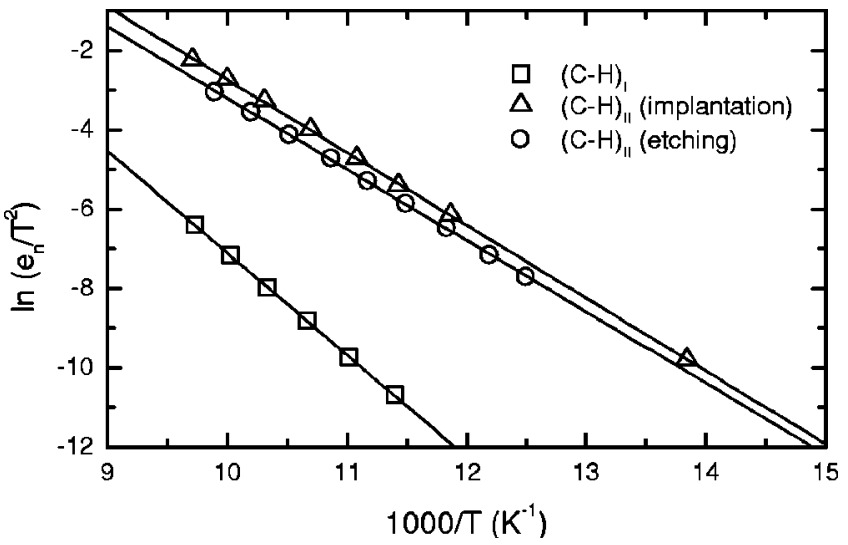

FIG. 3. Arrhenius plots for the electron emissions from $(\mathrm{C}-\mathrm{H})_{\mathrm{I}}$ and $(\mathrm{C}-\mathrm{H})_{\mathrm{II}}$.

dimensional Poole-Frenkel effect expected for an electron trapped by a positively charged center. ${ }^{20}$

A close correlation exists between the Arrhenius plots of the $(\mathrm{C}-\mathrm{H})_{\mathrm{II}}$ level measured in the implanted, annealed samples, and in the etched samples. This supports our suggestion that these are identical levels. In both cases, the activation enthalpy is obtained as $0.16 \mathrm{eV}$. No electric-field dependence of the emission process is observed in the two sets of samples as shown in Fig. 4. The directly measured electron capture cross section of $(\mathrm{C}-\mathrm{H})_{\mathrm{II}}, 2 \times 10^{-16} \mathrm{~cm}^{2}$, is a factor 100 less than that of $(\mathrm{C}-\mathrm{H})_{\mathrm{I}}$, and exhibits no barrier. These results suggest that $(\mathrm{C}-\mathrm{H})_{\mathrm{II}}$ is a deep acceptor with a level at $E_{c}-0.16 \mathrm{eV}$. The acceptor nature of $(\mathrm{C}-\mathrm{H})_{\mathrm{II}}$ is in disagreement with the conclusions reached by Endrös et al. ${ }^{7}$ and Kamiura et al..$^{9,19}$

\section{Uniaxial stress measurements}

Preliminary in situ uniaxial stress measurements were carried out for the $(\mathrm{C}-\mathrm{H})_{\mathrm{I}}$ defect. Figure 5 shows a Laplace DLTS spectrum of $(\mathrm{C}-\mathrm{H})_{\mathrm{I}}$ obtained at $100 \mathrm{~K}$ under zero and $0.6 \mathrm{GPa}$ stress along the $\langle 100\rangle$ direction. The spectrum shows a clear splitting into two separate lines. The splitting

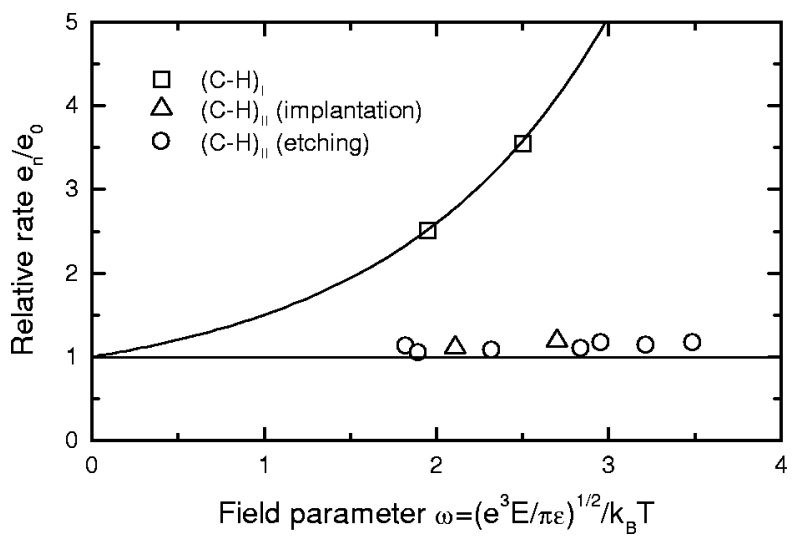

FIG. 4. Comparison of the emission rates of $(\mathrm{C}-\mathrm{H})_{\mathrm{I}}$ and $(\mathrm{C}-\mathrm{H})_{\mathrm{II}}$ as a function of field, showing the Pool-Frenkel effect expected for a single donor for $(\mathrm{C}-\mathrm{H})_{\mathrm{I}}$ and the absence of such an effect for $(\mathrm{C}-\mathrm{H})_{\mathrm{II}}$. 


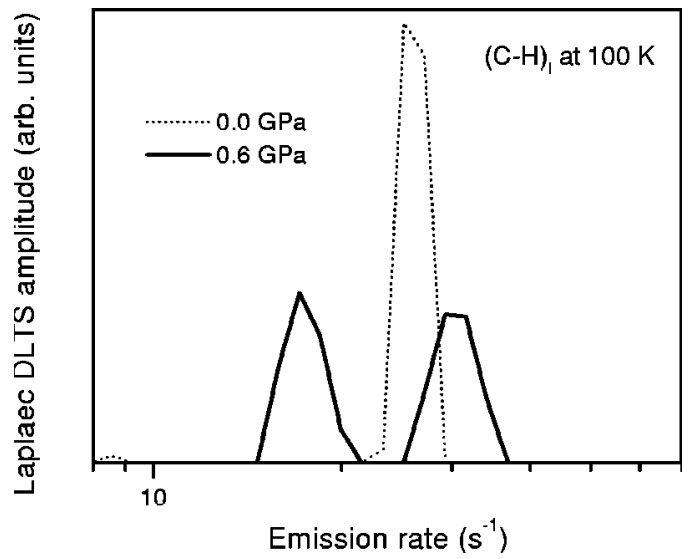

FIG. 5. Laplace DLTS spectrum of $(\mathrm{C}-\mathrm{H})_{\mathrm{I}}$ measured at $100 \mathrm{~K}$ under zero and 0.6 GPa stress along the $\langle 100\rangle$ direction. The line splitting shows that the complex has a symmetry lower than trigonal symmetry.

is linear in stress with a stress coefficient of $8 \mathrm{meV} / \mathrm{GPa}$. The intensity ratio of the two lines in Fig. 5 is approximately 1:1, but this ratio was found to change during the measurement series, suggesting that stress-induced alignment takes place at the measurement temperature. Further, the small separation of the two lines complicates the computation of the spectral density function, introducing additional uncertainty on the intensity ratio. As a consequence, it was not possible to establish the exact symmetry class of $(\mathrm{C}-\mathrm{H})_{\mathrm{I}}$, but as the line splits under $\langle 100\rangle$ stress, its symmetry is lower than trigonal.

A detailed piezospectroscopic analysis of $(\mathrm{C}-\mathrm{H})_{\mathrm{II}}$ was carried out in the etched samples. Figure 6 shows Laplace DLTS spectra of $(\mathrm{C}-\mathrm{H})_{\mathrm{II}}$ measured at $85 \mathrm{~K}$ with no stress and under uniaxial stress along three major directions. The zero-stress line splits into two components with approximate intensity

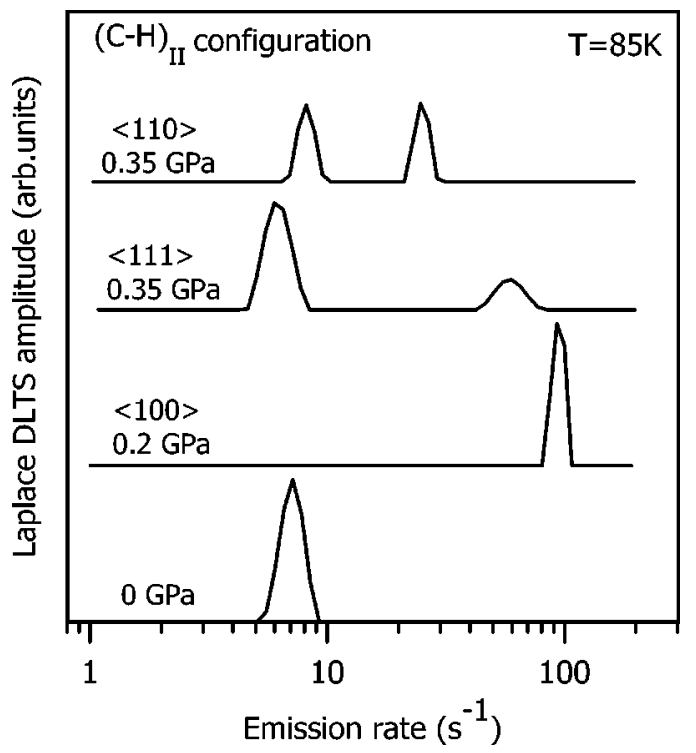

FIG. 6. Laplace DLTS spectra of $(\mathrm{C}-\mathrm{H})_{\mathrm{II}}$ measured at $85 \mathrm{~K}$ with zero stress and under uniaxial stress along three major directions. The line splittings show the trigonal symmetry of the center.

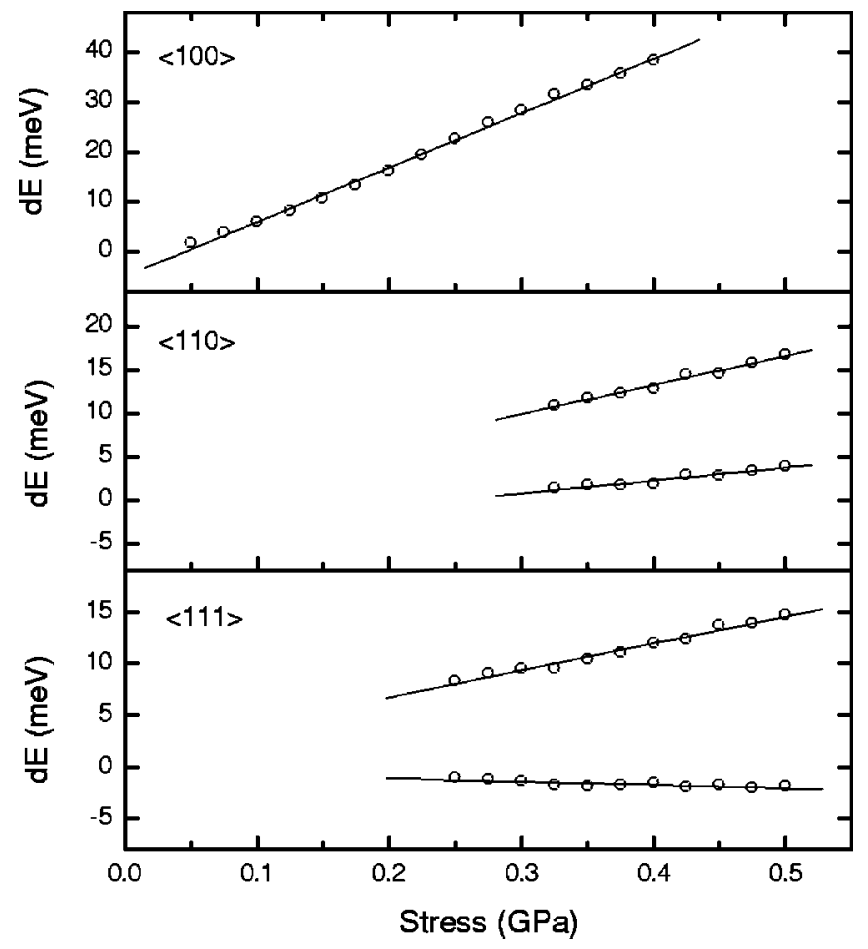

FIG. 7. Energy shifts versus applied stress for the individual lines of $(\mathrm{C}-\mathrm{H})_{\mathrm{II}}$ under stress along the $\langle 100\rangle,\langle 110\rangle$, and $\langle 111\rangle$ directions. The energy shifts have been obtained as $d E$ $=k T \ln \left[e_{n}(P) / e_{n}(0)\right]$, where $e_{n}(P)$ is the directly measured electron emission rate at the given stress, and $T=85 \mathrm{~K}$ is the measurement temperature. A positive slope means that the energy level approaches the conduction band. The origin points have not been included in the linear fits.

ratios 1:1 for $\langle 110\rangle$ stress and 3:1 for $\langle 111\rangle$ stress. No line splitting is observed for $\langle 100\rangle$ stress. This splitting pattern demonstrates the trigonal symmetry of the center, in agreement with previous results. ${ }^{9,21,22}$ Figure 7 depicts the stressinduced energy shifts of the individual lines under $\langle 100\rangle$, $\langle 110\rangle$, and $\langle 111\rangle$ stress. The splitting is linear in stress and is $20 \mathrm{meV} / \mathrm{GPa}$ for $\langle 110\rangle$ stress, and $29 \mathrm{meV} / \mathrm{GPa}$ for $\langle 111\rangle$ stress. The experimental ratio of the splitting along $\langle 111\rangle$ to $\langle 110\rangle$ is consistent with the 4:3 ratio expected for a trigonal center. The values of splitting for $(\mathrm{C}-\mathrm{H})_{\mathrm{II}}$ are given in Table VI.

The application of a uniaxial stress at temperatures, where the defects can reorient leads to a preferential alignment. This is seen as a change in the amplitude ratio of the split Laplace DLTS lines. No alignment of $(\mathrm{C}-\mathrm{H})_{\mathrm{II}}$ is observed below $250 \mathrm{~K}$, but application of a $\langle 111\rangle$ stress around RT is found to increase the intensity of the low-frequency line relative to the intensity of the high-frequency line. Complete alignment of the $(\mathrm{C}-\mathrm{H})_{\mathrm{II}}$ complex under $\langle 111\rangle$ stress changes the 3:1 ratio of the two lines to a population aligned in one form. As described in the introduction, the piezospectroscopic tensor component $B_{3}$ can be found from the relative amplitudes of the two components in steady state under stress. The equilibrium distribution of the negatively charged $(\mathrm{C}-\mathrm{H})_{\mathrm{II}}$ complex was reached at $330 \mathrm{~K}$ by applying the stress at zero bias for sufficient time to reach the steady-state con- 
TABLE VI. Calculated and experimental values for the unique stress-energy tensor component $B_{3}(\mathrm{eV})$ for different charge states, and splitting of levels, $\partial E / \partial \sigma \mathrm{meV} / \mathrm{GPa}$, for $\langle 110\rangle$ and $\langle 111\rangle$ stresses.

\begin{tabular}{lcccccc}
\hline \hline & Defect & $B_{3}(+)$ & $B_{3}(0)$ & $B_{3}(-)$ & $\frac{\partial E}{\partial \sigma}, \sigma \|\langle 110\rangle$ & $\frac{\partial E}{\partial \sigma}, \sigma \|\langle 111\rangle$ \\
\hline Theory $^{\mathrm{a}}$ & $\mathrm{CH}_{1 \mathrm{BC}}$ & -6.39 & -8.78 & -10.41 & 10.2 & 13.6 \\
Theory $^{\mathrm{b}}$ & $\mathrm{CH}_{1 \mathrm{BC}}$ & -6.05 & -8.98 & -12.04 & 18.8 & 25.1 \\
Theory & $\mathrm{CH}_{1 \mathrm{BC}}$ & & -8.84 & -11.29 & 15.3 & 20.4 \\
Experiment & $(\mathrm{C}-\mathrm{H})_{\mathrm{II}}$ & & $\sim-7.0$ & -10.6 & 20 & 29 \\
\hline \hline
\end{tabular}

${ }^{\mathrm{a}} \mathrm{MP}^{2} k$ points, $\mathrm{H}\left(s_{3} p_{3}\right), \mathrm{C}\left(s_{4} p_{4} d_{4}\right)$, and $\mathrm{Si}\left(s_{4} p_{4} d_{2}\right)$ basis.

${ }^{\mathrm{b}} \mathrm{MP}^{2} k$ points, $\mathrm{H}\left(s_{3} p_{3}\right), \mathrm{C}\left(s_{4} p_{4}\right)$, and $\mathrm{Si}\left(s_{4} p_{4}\right)$ with bond-center polarization basis.

${ }^{c} \mathrm{MP}^{4} k$ points, $\mathrm{H}\left(s_{3} p_{3}\right), \mathrm{C}\left(s_{4} p_{4} d_{4}\right)$, and $\mathrm{Si}\left(s_{4} p_{4} d_{2}\right)$ basis.

dition. Subsequently, the sample was quickly cooled to $85 \mathrm{~K}$, where the amplitude ratio of Laplace DLTS lines was evaluated. Figure 8 shows the steady-state occupancy ratio of the negatively charged complex at $330 \mathrm{~K}$ as a function of applied stress. The energy separation is linear in stress with stress coefficient $89 \mathrm{meV} / \mathrm{GPa}$. Table VI gives the corresponding value of the piezospectroscopic tensor component $B_{3}(-)$ together with $B_{3}(-/ 0)$, which is found from $B_{3}(-)$ and the measured level splitting.

\section{THEORETICAL RESULTS}

Figure 1 shows configurations of $\mathrm{C}-\mathrm{H}$ defects considered in this study. The most stable site $\left(\mathrm{CH}_{1 \mathrm{BC}}\right)$ is where $\mathrm{H}$ is bound to carbon in a perturbed bond-center configuration with a binding energy of $0.98 \mathrm{eV}$ in the neutral state and about half of this in both the negative and positive charge states. The calculated levels of this structure are at $E_{v}$ +0.31 and $E_{c}-0.30$ for the $(0 /+)$ and $(-/ 0)$ levels, respectively, with the $(-/ 0)$ level almost coincidental with the $(0 /+)$ level at $E_{c}-0.27$ obtained for isolated bond-centered hydrogen. The electrical activity of the $(0 /+)$ and $(-/ 0)$ levels of $\mathrm{CH}_{1 \mathrm{BC}}$ is associated with a "dangling" Si bond left by the formation of the adjacent $\mathrm{C}-\mathrm{H}$ unit.

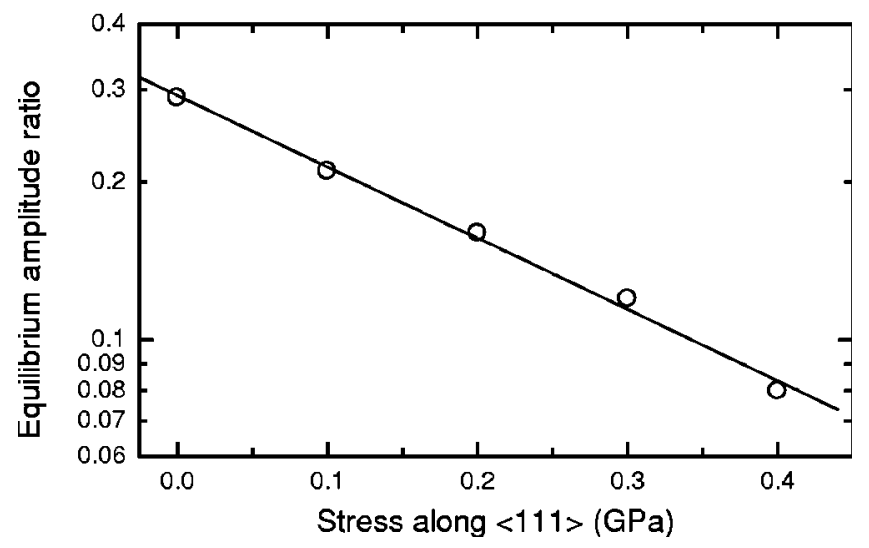

FIG. 8. 330-K steady-state occupancy ratio of the two configurations of the negatively charged $(\mathrm{C}-\mathrm{H})_{\mathrm{II}}$ complex under $\langle 111\rangle$ stress as a function of applied stress. The ratio is the intensity ratio of the high-frequency and the low-frequency Laplace DLTS lines measured at $85 \mathrm{~K}$ after zero-bias stress annealing at $330 \mathrm{~K}$ for sufficient time to reach the steady-state condition.
The metastable configuration with symmetry $C_{1 h}$, $\mathrm{CH}_{2 \mathrm{BC}}^{+}$, has been previously connected with a prominent optical center, stable to $\sim 225 \mathrm{~K}$, found in low-temperature proton implanted $\mathrm{Si}: \mathrm{C}^{23}$ and is only $0.2 \mathrm{eV}$ higher in energy than $\mathrm{CH}_{1 \mathrm{BC}}^{+}$(Table I). In the work of Hoffmann et al., ${ }^{23}$ local vibrational modes corresponding to perturbed $\mathrm{H}_{\mathrm{BC}}^{+}$and $\mathrm{C}_{\mathrm{s}}$ defects were found but the electrical activity of the defects was not investigated. Our present calculations give the $(0 /$ + ) level of the $\mathrm{CH}_{2 \mathrm{BC}}$ defect at $E_{c}-0.40 \mathrm{eV}$, slightly lower in the gap than the $E_{c}-0.27 \mathrm{eV}$, obtained for isolated $\mathrm{H}_{\mathrm{BC}}$. Thus, the properties of this defect are similar to isolated $\mathrm{H}$. In the negative charge state, a further $C_{2 v}$ minima is found, $\mathrm{H}_{1 T d}^{-}$, with the hydrogen lying at a perturbed $T_{d}$ site near $\mathrm{C}_{\mathrm{s}}$. The further antibonding structure, $\mathrm{CH}_{2 \mathrm{AB}}$, is found to be high energy for both the neutral and negative charge states.

The trigonal configuration $\mathrm{CH}_{1 \mathrm{BC}}$ and $\mathrm{CH}_{1 \mathrm{AB}}$ have been suggested many times to be stable centers ${ }^{24-27}$ although there have been disputes about their relative energies. These centers were not detected in the earlier optical study possibly because of the small transition dipole associated with $\mathrm{C}-\mathrm{H}$ bonds. We find the calculated donor level of configuration $\mathrm{CH}_{1 \mathrm{BC}}$ lies very low in the gap at $E_{v}+0.31 \mathrm{eV}$. This level is close to an experimental donor level $\left(H_{1}\right)$ at $E_{v}+0.33 \mathrm{eV}$ previously assigned to $\mathrm{C}_{\mathrm{s}}-\mathrm{H}$ defect and found in $p$-Si. ${ }^{8}$ The electrical activity can be thought to arise from the breaking of a $\mathrm{Si}-\mathrm{C}$ bond and is mostly associated with the Si dangling bond neighboring the $\mathrm{C}-\mathrm{H}$ unit. $^{28}$

Of interest here are the acceptor levels of the configurations $\mathrm{CH}_{1 \mathrm{BC}}$ and $\mathrm{CH}_{1 \mathrm{AB}}$ calculated to be $E_{c}-0.30$ and $E_{c}$ $-0.63 \mathrm{eV}$ as shown in Tables III and V. We note that these configurations have the same trigonal symmetry but $\mathrm{CH}_{1 \mathrm{BC}}$ is more stable except possibly in the negative charge state, where its energy is within $0.2 \mathrm{eV}$ of $\mathrm{CH}_{1 \mathrm{AB}}$. However, the calculations show that the acceptor level of $\mathrm{CH}_{1 \mathrm{BC}}$, unlike that of $\mathrm{CH}_{1 \mathrm{AB}}$, is quite close at $E_{c}-0.30 \mathrm{eV}$ to that of $(\mathrm{C}-\mathrm{H})_{\mathrm{II}}$ at $E_{c}-0.16 \mathrm{eV}$. This lends further evidence that $(\mathrm{C}-\mathrm{H})_{\mathrm{II}}$ is associated with the acceptor level of $\mathrm{CH}_{1 \mathrm{BC}}$.

We now discuss the stress response of $\mathrm{CH}_{1 \mathrm{BC}}$. For a trigonal defect there is only one independent component of the stress tensor. If $B_{3}$ is the value along the trigonal axis, then $B_{1}=B_{2}=-B_{3} / 2$. The calculated $B_{3}(q)$ components of $\mathrm{CH}_{1 \mathrm{BC}}$ are given in Table VI with their dependence on $k$-point sampling. The signs and magnitudes of the $B_{3}(0)$ and $B_{3}(-)$, which control the fractional alignment of the 
defects are in good agreement with the observed values for $(\mathrm{C}-\mathrm{H})_{\mathrm{II}}$. The experimental value of $B_{3}(0) \sim-7 \mathrm{eV}$ has been estimated from the value of $B_{3}(-)$ and the experimental level splitting. $B_{3}(+)$ has not been found as it requires experiments on $p$-type material. The difference in $B$ between charge states, $B(-/ 0)$ determines the splitting of the electrical level. The computed splitting of the level for $\langle 110\rangle$ and $\langle 111\rangle$ stresses found from the calculated $B_{3}$ values are given in Table VI and in reasonable agreement (error less than $\sim 30 \%$ ) with the observed data especially for the more accurate $k$-point sampling. The calculations of the stress response reinforce the conclusions drawn from the site energies and levels, that $(\mathrm{C}-\mathrm{H})_{\mathrm{II}}$ is the acceptor level associated with $\mathrm{CH}_{1 \mathrm{BC}}$.

\section{DISCUSSION}

$(\mathrm{C}-\mathrm{H})_{\mathrm{I}}$, which is produced in low-temperature proton implanted $\mathrm{Si}: \mathrm{C}$, is found to possess a capture cross section of $2 \times 10^{-14} \mathrm{~cm}^{2}$, which together with the observation of a Poole-Frenkel effect confirms the donor nature of this level. Only two low-energy structures are found theoretically for the positive charge state, $\mathrm{CH}_{1 \mathrm{BC}}$ and $\mathrm{CH}_{2 \mathrm{BC}}$. The $(0 /+)$ electrical level of $\mathrm{CH}_{2 \mathrm{BC}}$ is in excellent agreement with $(\mathrm{C}-\mathrm{H})_{\mathrm{I}}$. This defect configuration has previously been observed by infrared absorption ${ }^{23}$ in a similar material

The observed level of $(\mathrm{C}-\mathrm{H})_{\mathrm{II}}$ at $E_{c}-0.16 \mathrm{eV}$ is found to possess a directly measured electron capture cross section of $2 \times 10^{-16} \mathrm{~cm}^{-2}$. This is a value expected for capture into a neutral center and so is consistent with the state being a deep acceptor. A much larger value would be measured for capture into a Coulombic attractive state and so, on this evidence alone it seems extremely unlikely that the defect could be a donor. In addition, at the fields we used $\left(<10^{4} \mathrm{~V} / \mathrm{cm}\right)$, the state displays no Pool-Frenkel effect. The calculated electrical levels of the stable structures for hydrogen near carbon display only one reasonable candidate for this level, which is both low in energy for both charge states, and possesses a level in the required part of the gap. This defect, $\mathrm{CH}_{1 \mathrm{BC}}$, possesses an acceptor level which is coincidentally close to the isolated $\mathrm{H}_{\mathrm{BC}}$ donor. The observed stress response of $(\mathrm{C}-\mathrm{H})_{\mathrm{II}}$ is found to be in good agreement with the calculated $B$ tensors of $\mathrm{CH}_{1 \mathrm{BC}}^{0}$ and $\mathrm{CH}_{1 \mathrm{BC}}^{-}$, lending further weight to the assignment.

\section{SUMMARY}

The electrical activity of $\mathrm{C}_{\mathrm{s}}-\mathrm{H}$ defects has been investigated in a combined theoretical and experimental study. We find that low-temperature proton implantation leads to a modified bond-center species, $(\mathrm{C}-\mathrm{H})_{\mathrm{I}}$, acting as a donor and where $\mathrm{H}$ lies between two $\mathrm{Si}$ atoms remote from carbon. However, at room temperature the stable defect is one with trigonal symmetry with $\mathrm{H}$ bonded to $\mathrm{C}$. This possesses an acceptor level at $E_{c}-0.16 \mathrm{eV}$ lying above a donor level at $E_{v}+0.33 \mathrm{eV}$. Theory has established that the stable trigonal center with properties consistent with the observed levels and piezospectroscopic behavior is one in which $\mathrm{H}$ lies at a bond center adjacent to $\mathrm{C}$. It seems likely that in the negative charge state two other structures may also coexist, with $\mathrm{H}$ either at an antibonding site to $\mathrm{C}$, or trapped at a nearby $T_{d}$ site.

The electrical activity of the two experimentally observed configurations have very different origins, with $(\mathrm{C}-\mathrm{H})_{\mathrm{I}}$ behaving like a bond-centered $\mathrm{H}$ atom with two nearly symmetric overlapping Si orbitals, while $(\mathrm{C}-\mathrm{H})_{\mathrm{II}}$ is similar to a dangling Si bond but adjacent to a $\mathrm{C}-\mathrm{H}$ unit. The position and splitting of the acceptor level under uniaxial stress are close to the theoretical estimates and the fractional alignment in good agreement for both charge states. Remarkably then, the presence of carbon then converts $\mathrm{H}$ into a positive- $U$ defect. Finally, we note that the development of the stress Laplace DLTS technique described here enables the stressenergy tensor to be found and compared with other measurements or theory. This, when extended to other defects and materials, would considerably aid in the assignment of electronic traps to specific defects.

\section{ACKNOWLEDGMENTS}

Discussions with B. Bech Nielsen, V. P. Markevich, and R. C. Newman are acknowledged. This work has been supported in part by the Royal Academy of Engineering and the Engineering and Physical Science Research Council in U.K., the State Committee for Scientific Research Grant No. 4T11B02123 in Poland, and by the Danish National Research Foundation through the Aarhus Center for Atomic Physics (ACAP).
${ }^{1}$ B. Holm, K. Bonde Nielsen, and B. Bech Nielsen, Phys. Rev. Lett. 66, 2360 (1991).

${ }^{2}$ K. Bonde Nielsen, B. Bech Nielsen, J. Hansen, E. Andersen, and J. U. Andersen, Phys. Rev. B 60, 1716 (1999).

${ }^{3}$ C. G. Van de Walle, Y. Bar-Yam, and S. T. Pantelides, Phys. Rev. Lett. 60, 2761 (1988).

${ }^{4}$ B. Hitti, S. R. Kreitzman, T. L. Estle, E. S. Bates, M. R. Dawdy, T. L. Head, and R. L. Lichti, Phys. Rev. B 59, 4918 (1999).

${ }^{5}$ K. Bonde Nielsen, L. Dobaczewski, S. Søgård, and B. Bech Nielsen, Physica B 308, 134 (2001).

${ }^{6}$ K. Bonde Nielsen, L. Dobaczewski, S. Søgård, and B. Bech
Nielsen, Phys. Rev. B 65, 075205 (2002).

${ }^{7}$ A. Endrös, Phys. Rev. Lett. 63, 70 (1989).

${ }^{8}$ Y. Kamiura, M. Tsutsue, Y. Tamashita, F. Hashimoto, and K. Okuno, J. Appl. Phys. 78, 4478 (1995).

${ }^{9}$ Y. Kamiura, K. Fukuda, Y. Yamashita, and T. Ishiyama, Defect Diffus. Forum 183, 25 (2000).

${ }^{10}$ L. Dobaczewski, P. Kaczor, I. D. Hawkins, and A. R. Peaker, J. Appl. Phys. 76, 194 (1994).

${ }^{11}$ G. D. Watkins, in Early Stages of Oxygen Precipitation in Silicon, Vol. 17 of NATO Advanced Studies Institute, Series B: Physics, edited by R. Jones (Kluwer Academic Publishers, Dordrecht, 
1996), p. 1.

${ }^{12}$ A. S. Kaminskii and E. V. Lavrov, Solid State Commun. 106, 751 (1998).

${ }^{13} \mathrm{R}$. Jones and P. R. Briddon, The ab initio Cluster Method and the Dynamics of Defects in Semiconductors, Semiconductors and Semimetals Vol. 51A (Academic Press, Boston, 1998), Chap. 6.

${ }^{14}$ J. Coutinho, R. Jones, P. R. Briddon, and S. Öberg, Phys. Rev. B 62, 10824 (2000).

${ }^{15}$ J. P. Perdew and A. Zunger, Phys. Rev. B 23, 5048 (1981).

${ }^{16}$ H. J. Monkhorst and J. D. Pack, Phys. Rev. B 13, 5188 (1976).

${ }^{17}$ J.-W. Jeong and A. Oshiyama, Phys. Rev. B 64, 235204 (2001).

${ }^{18}$ J. Coutinho, V. J. B. Torres, A. Resende, R. Jones, and P. R. Briddon, Phys. Status Solidi B (to be published).

${ }^{19}$ M. Yoneta, Y. Kamiura, and F. Hashimoto, J. Appl. Phys. 70, 1295 (1991).

${ }^{20}$ S. D. Ganichev, E. Ziemann, I. N. Yassievich, W. Prettl, A. A. Istratov, and E. R. Weber, Phys. Rev. B 61, 10361 (2000).
${ }^{21}$ Y. Kamiura, N. Ishiga, and Y. Yamashita, Jpn. J. Appl. Phys., Part 2 36, L1419 (1997).

${ }^{22}$ K. Fukuda, Y. Kamiura, and Y. Yamashita, Physica B 273-274, 184 (1999).

${ }^{23}$ L. Hoffmann, E. V. Lavrov, B. Bech Nielsen, B. Hourahine, R. Jones, S. Öberg, and P. R. Briddon, Phys. Rev. B 61, 16659 (2000).

${ }^{24}$ D. M. Maric, P. F. Meier, and S. K. Estreicher, Phys. Rev. B 47, 3620 (1993).

${ }^{25}$ C. Kaneta and H. Katayama-Yoshida, Solid State Commun. 93, 460 (1995).

${ }^{26}$ A. Mainwood, Mater. Sci. Forum 258-263, 253 (1997).

${ }^{27}$ P. Leary, R. Jones, and S. Öberg, Phys. Rev. B 57, 3887 (1998).

${ }^{28}$ O. Andersen, L. Dobaczewski, A. R. Peaker, K. B. Nielsen, B. Hourahine, R. Jones, P. R. Briddon, and S. Öberg, Physica B 308, 139 (2001). 